высококачественной зеленой массы с 2-х укосов по 275 - 355 ц/га, в 1,5 - 2 раза превышая сбор зеленой массы с естественного сенокоса.

Высокая противоэрозионная способность в борьбе с водной эрозией козлятника восточного и вязеля пестрого, получения высококачественной продукции, низкая затратность на их возделывание создают перспективу выращивания этих культур в почвозащитных севооборотах гор.

$$
* * *
$$

1. Адиньяев Э.Д., Джериев Т.У., Кучиев С.Э. Экологическая оценка возделывания полевых культур в субальпийском поясе // Тезисы докладов научно-практической конференции «Экологически безопасные технологии в сельском производстве XXI века» - Владикавказ, Иристон, 2000 - 575 $577 \mathrm{c}$.

2. Адиньяев Э.Д., Абаев А.А., Мисик Н.А., Мамиев Д.М., Кучиев С.Э., Доева Л.Ю., Тедеева А.А., Кокоев Л.П., Шалыгина А.А. Схемы почвозащитных севооборотов в горных условиях РСОАлания // Владикавказ, 2010.

3. Абаев А.А., Шорин П.М., Бзиков М.А. Освоение интенсивных экологизированных севооборотов основной путь повышения урожайности с.-х. культур и плодородия почвы». Сб. трудов СОАНВШ РФ, 2005, № 3 .

4. Бораева З.Б., Бекузарова С.А. Новые нетрадицион-ные растения и перспективы их использования - IV Международный симпозиум 9 - 14 июня 2003 г. том II, г. Пущино, 2003.

5. Мамиев Д.М., Абаев А.А., Тедеева А.А. Биологическая интенсификация звена зернопропашного севооборота//Научная жизнь. 2014. № 3. С. 26-29.

6. Мамиев Д.М., Абаев А.А., Тедеева А.А., Кучиев С.Э. Разработка адаптивно-ландшафтной системы земледелия для предгорной зоны РСО-Алания// Известия Горского государственного аграрного университета. 2012. Т. 49. № 4. С. 79-83.

7. Тедеева В.В., Абаев А.А., Тедеева А.А., Хохоева Н.Т. Показатели фотосинтетической деятельности нута в зависимости от способа посева, нормы высева и гербицида // Современные проблемы науки и образования. 2015. № 1-1. С. 1696.

\title{
Сорокопудов B.Н., Мацнева A.E. \\ Перспективы и направления использования дикорастущих многолетних растений в условиях городских агломераций
}

ФГБОУ ВО РГАУ-МСХА им. К.А. Тимирязева

(Россия, Москва)

doi: $10.18411 / \mathrm{j}-02-2021-26$

idsp: ljournal-02-2021-26

\section{Аннотация}

В работе рассмотрены вопросы внедрения в городскую среду нового типа устойчивых посадок из травянистых растений в виде природных видов, допущенных по регламенту Красной книги г. Москвы, с учетом их высокой устойчивости к экологическим условиям, часто меняющимся в условиях городских агломераций. Предложенные виды создают высокодекоративные и устойчивые массивы, являющиеся основой любого фитоценоза. Кроме того, они придают городу неповторимый облик, соединяя его с естественным зеленым поясом города Москвы. Мотивируют и информируют население и жителей об ассортименте, декоративных качествах и полезности диких видов растений.

Ключевые слова: дикорастущие виды, лекарственные и декоративные культуры, растения красной книги г. Москвы, фитоценоз, расширение ассортимента.

13 ноября 2007 г Правительство Москвы приняло постановление №996-ПП О генеральной схеме озеленения г. Москвы на период до 2020 г., где отмечается, что одним из основных направлений разработки схемы озеленения города является 
формирование непрерывной системы природных территорий, в которой ведущую роль играет «природоподобный» ландшафт, способный к самовосстановлению (с помощью экологической реабилитации).

Для создания природного ландшафта, устойчивого к меняющимся факторам городской среды, повышением урбанизации важно создавать и внедрять «естественные насаждения» как древесные, так и травянистые, так, как только вместе они могут создать устойчивый фитоценоз [4, 12].

В связи с введенными санкциями резко возросла стоимость посадочного материала. Поэтому одной из мер по сохранению стоимости и затрат на приобретение посадочного материала, является уход или отказ от традиционных летников, семена которых, производятся за рубежом. Поэтому переход на природные «виды-дикоросы», которые не имеют себестоимости и затраты на них распространяются только на пересадку в оптимальные сроки, контейнеровку и работы по посадке $[3,6,10,11]$.

На территории Новой Москвы, отводимой под застройку, произрастает много диких видов растений ценных для озеленения. Есть места, где эти виды сильно разрослись, например, территории под ЛЭП, разделительные полосы широких магистралей - это все «доноры-источники» нового посадочного материала.

Современные эколого-натуралистическое видение цветников и напочвенного покрова способствует расширению ассортимента травянистых растений с привлечением декоративных многолетников и трав, близких по образу к растениям природных фитогеоцентозов, а также растений, способных произрастать совместно, на одной территории при одинаковых экологических условиях $[2,8,13]$.

Закон города Москвы от 30.04.2014 г №18 (ред. от 17.05.2018 г.) «О благоустройстве в городе Москве». Данный документ регламентирует, каким образом приводят благоустройство территорий, содержат и проводят уход за созданными объектами. В нем отражены вопросы размещения конструктивных и составляющих объектов, дворовые территории, подверженные наиболее сильному воздействию антропогенных факторов; содержит формы, паспорта объекта в установленной форме. В нем все объекты благоустройства делятся на категории по принадлежности к собственности земли на территории г. Москвы [5]. Перед устройством природных зон отдыха и других категорий для отдыха - скверов, бульваров, набережных, необходимо решить этот вопрос. А также здесь регламентируется вопрос об использовании «неудобных территорий» в связи с низкой озелененностью городов. Эти территории, так же могут стать интересной экспериментальной площадкой для испытания диких видов в новых типах посадки (это внешняя поверхность крыши зданий и стены сооружений).

Красная книга г. Москвы - это официальный документ правительства Москвы, в котором приведена информация о редких и исчезающих видах растений на территории города, о причинах их уничтожения, современное состояние, содержит программу действий по сохранению видов и их восстановлению. Обновляется раз в 5-7 лет [7, 9].

Результаты и обсужжения. В результате работы было подобрано 11 видов дикорастущих растений (таблица 1) для городского озеленения, с целью создания устойчивых и долговечных посадок. Изучение проводили в условиях городских посадок в общественных местах города Москвы. Для всех изученных видов предложены оптимальные условия произрастания по освещенности, влажности почвы, механическому составу. Приведены основные морфологические признаки (высота, размер цветка, размер листа, тип соцветия), фенологические признаки (сроки цветения по месяцам). Для проведения правильного размещения данных видов в ландшафте, приведены рекомендации по типу посадки. 
Таблица 1

Морфологические признаки, направления использования, условия произрастания и оченка устойчивости, декоративности дикорастущих видов, рекомендуемых для

\begin{tabular}{|c|c|c|c|c|c|c|}
\hline № & $\begin{array}{c}\text { Вид, латынь, } \\
\text { семейство }\end{array}$ & $\begin{array}{l}\text { Морфологи- } \\
\text { ческие } \\
\text { признаки }\end{array}$ & $\begin{array}{c}\text { Феноло- } \\
\text { гические } \\
\text { признаки, } \\
\text { месяц н. } \\
\text { отраст-я, } \\
\text { пик дек- } \\
\text { ти (дн.) } \\
\end{array}$ & $\begin{array}{l}\text { Занесен } \\
\text { в КК г. } \\
\text { Москвы } \\
\text { +/-, } \\
\text { категор } \\
\text { ия }\end{array}$ & $\begin{array}{c}\text { Предпочти- } \\
\text { тельные условия } \\
\text { произрастания } \\
\text { (свет, почва, } \\
\text { влажность) }\end{array}$ & $\begin{array}{c}\text { Направление } \\
\text { использования } \\
\text { в новых типах } \\
\text { посадки }\end{array}$ \\
\hline 1 & $\begin{array}{c}\text { Медуница неясная } \\
\text { (Pulmanaria } \\
\text { obcura) }\end{array}$ & $\begin{array}{c}\mathrm{h}=30 \text { см, лист } \\
\text { простой, } \\
\text { соцветие Ø35 } \\
\text { см, сине- } \\
\text { красное. }\end{array}$ & $\begin{array}{c}\text { V } \\
\text { (30 дней) }\end{array}$ & $\begin{array}{c}\text { +/ III } \\
\text { категор } \\
\text { ия }\end{array}$ & $\begin{array}{l}\text { увлажненные, } \\
\text { тенистые места, } \\
\text { леса, подлесок }\end{array}$ & $\begin{array}{c}\text { овраги, канавы, } \\
\text { нарушенные } \\
\text { территории, } \\
\text { теневые } \\
\text { миксбордеры, } \\
\text { теневые склоны }\end{array}$ \\
\hline 2 & $\begin{array}{c}\text { Купальница } \\
\text { европейская } \\
\text { (Trollius europaeus) }\end{array}$ & $\begin{array}{c}\mathrm{h}=50 \text { см, лист } \\
\text { резной, } \\
\text { цветки Ø3 см, } \\
\text { желтые. }\end{array}$ & $\begin{array}{c}\text { V } \\
\text { (15 дней) }\end{array}$ & $\begin{array}{c}\text { +/ III } \\
\text { категор } \\
\text { ия }\end{array}$ & $\begin{array}{c}\text { умеренная } \\
\text { влажность, } \\
\text { песчаные почвы }\end{array}$ & $\begin{array}{c}\text { опушки, } \\
\text { поляны, } \\
\text { миксбордеры, } \\
\text { цветочные } \\
\text { группы } \\
\end{array}$ \\
\hline 3 & $\begin{array}{c}\text { Осока } \\
\text { пушистоплодная } \\
\text { (Carex lasiocarpa) }\end{array}$ & $\begin{array}{c}\text { h= } 35 \text { см. } \\
\text { лист, } \\
\text { линейный } \\
\text { опушенные } \\
\text { корневища, } \\
\text { соцв. метель- } \\
\text { чатое } \\
\end{array}$ & $\begin{array}{c}\text { V } \\
\text { (15 дней) }\end{array}$ & $\begin{array}{c}\text { +/ II } \\
\text { категор } \\
\text { ия }\end{array}$ & $\begin{array}{c}\text { влажные места, } \\
\text { полутень }\end{array}$ & $\begin{array}{c}\text { водоемы, } \\
\text { береговая } \\
\text { линия, низины, } \\
\text { овраги, теневые } \\
\text { миксбордеры }\end{array}$ \\
\hline 4 & $\begin{array}{c}\text { Пушица } \\
\text { влагалищная } \\
\text { (Eriophorum } \\
\text { vaginatum) }\end{array}$ & $\begin{array}{l}\mathrm{h}=30 \mathrm{cм} . \\
\text { образуют } \\
\text { плотную } \\
\text { кочку }\end{array}$ & $\begin{array}{c}\text { V } \\
\text { (10 дней) }\end{array}$ & $\begin{array}{c}\text { +/ II } \\
\text { категор } \\
\text { ия }\end{array}$ & $\begin{array}{l}\text { светолюбив, } \\
\text { влаголюбив }\end{array}$ & $\begin{array}{c}\text { водоемы, } \\
\text { береговая } \\
\text { линия, } \\
\text { набережные, } \\
\text { теневые } \\
\text { миксбордеры }\end{array}$ \\
\hline 5 & $\begin{array}{c}\text { Нивяник } \\
\text { обыкновенный } \\
\text { (Leucanthemum } \\
\text { vulgare) }\end{array}$ & $\begin{array}{c}\mathrm{h}=30 \text { см. } \\
\text { многолетние } \\
\text { корневища, } \\
\text { листья в } \\
\text { прикорневой } \\
\text { розетке }\end{array}$ & $\begin{array}{c}\text { VI } \\
\text { (20 дней) }\end{array}$ & $\begin{array}{c}\text { +/ III } \\
\text { категор } \\
\text { ия }\end{array}$ & $\begin{array}{l}\text { светолюбив, } \\
\text { влаголюбив }\end{array}$ & $\begin{array}{c}\text { широкая } \\
\text { амплитуда по } \\
\text { условиям, } \\
\text { нарушенная } \\
\text { территория, } \\
\text { цветники все } \\
\text { группы, склоны }\end{array}$ \\
\hline 6 & $\begin{array}{c}\text { Первоцвет } \\
\text { весенний } \\
\text { (Primula veris) }\end{array}$ & $\begin{array}{c}\mathrm{h}=15-20 \text { см. } \\
\text { раннецветущ } \\
\text { ий } \\
\text { многолетник. } \\
\text { соцветия } \\
\text { желтые, лист } \\
\text { простой } \\
\end{array}$ & $\begin{array}{c}\text { V } \\
\text { (25 дней) }\end{array}$ & $\begin{array}{c}\text { +/ III } \\
\text { категор } \\
\text { ия }\end{array}$ & $\begin{array}{l}\text { теневынослив, } \\
\text { влаголюбив, } \\
\text { смешенные леса, } \\
\text { подлесок. }\end{array}$ & $\begin{array}{c}\text { поляны, } \\
\text { опушки, } \\
\text { склоны, крыши, } \\
\text { цветники }\end{array}$ \\
\hline 7 & $\begin{array}{c}\text { Астрагал } \\
\text { солодколистный } \\
\text { (Astragalus } \\
\text { glycyphyllos) }\end{array}$ & $\begin{array}{c}\mathrm{h}=15 \text { см. } \\
\text { многолетник }\end{array}$ & $\begin{array}{l}\text { VI-VIII } \\
\text { (90 дней) }\end{array}$ & $\begin{array}{c}\text { +/ II } \\
\text { категор } \\
\text { ия }\end{array}$ & $\begin{array}{c}\text { теневынослив, } \\
\text { засухоустойчив. }\end{array}$ & $\begin{array}{c}\text { опушки, луга, } \\
\text { поляны, } \\
\text { миксбордеры, } \\
\text { придорожные } \\
\text { склоны } \\
\end{array}$ \\
\hline 8 & $\begin{array}{c}\text { Чина весенняя } \\
\text { (Lathyrus vernus) }\end{array}$ & $\begin{array}{c}\text { многолетние } \\
\text { корневища, } \\
\text { раннецветущ } \\
\text { ий. } \\
\end{array}$ & $\begin{array}{c}\text { V-VI } \\
\text { (15 дней) }\end{array}$ & $\begin{array}{c}\text { +/ III } \\
\text { категор } \\
\text { ия }\end{array}$ & $\begin{array}{c}\text { светолюбив, } \\
\text { теневынослив, } \\
\text { умеренная } \\
\text { влажность } \\
\end{array}$ & $\begin{array}{c}\text { опушки, } \\
\text { хвойные лиса, } \\
\text { теневые } \\
\text { цветники } \\
\end{array}$ \\
\hline 9 & $\begin{array}{c}\text { Горицвет } \\
\text { кукушкин } \\
\text { (Coronaria flos- } \\
\text { cuculi) }\end{array}$ & $\begin{array}{c}\mathrm{h}=45 \text { см. } \\
\text { травянистый } \\
\text { многолетник }\end{array}$ & $\begin{array}{c}\text { VI } \\
\text { (10 дней) }\end{array}$ & $\begin{array}{c}\text { +/ III } \\
\text { категор } \\
\text { ия }\end{array}$ & $\begin{array}{c}\text { сырые, } \\
\text { заболоченные } \\
\text { места, болота. }\end{array}$ & $\begin{array}{c}\text { берега, } \\
\text { водоемы, } \\
\text { теневые } \\
\text { влажные } \\
\text { цветники }\end{array}$ \\
\hline
\end{tabular}




\begin{tabular}{|c|c|c|c|c|c|c|}
\hline 10 & $\begin{array}{c}\text { Колокольчик } \\
\text { раскидистый } \\
\text { (Campanula patula } \\
\text { L.) } \\
\text { (Колокольчиковые } \\
\text { ) }\end{array}$ & $\begin{array}{c}\mathrm{h}=45 \text { см. } \\
\text { декоратив. } \\
\text { листья и соцв. }\end{array}$ & $\begin{array}{c}\text { VI } \\
\text { (15 дней) }\end{array}$ & $\begin{array}{c}\text { +/ II } \\
\text { категор } \\
\text { ия }\end{array}$ & $\begin{array}{c}\text { теневынослив, } \\
\text { влаголюбив }\end{array}$ & $\begin{array}{c}\text { поляны, } \\
\text { опушки, } \\
\text { склоны, ЛЭП, } \\
\text { цветники, } \\
\text { склоны с } \\
\text { кустарниками }\end{array}$ \\
\hline 11 & $\begin{array}{c}\text { Колокольчик } \\
\text { широколистный } \\
\text { (Campanula } \\
\text { latifolia) }\end{array}$ & $\begin{array}{c}\mathrm{h}=70 \text { см. } \\
\text { травянистый } \\
\text { многолетник, } \\
\text { с коротким } \\
\text { корневищем } \\
\end{array}$ & $\begin{array}{c}\text { VI } \\
\text { (20 дней) }\end{array}$ & $\begin{array}{c}\text { +/ III } \\
\text { категор } \\
\text { ия }\end{array}$ & $\begin{array}{c}\text { тенистые, сырые } \\
\text { места }\end{array}$ & $\begin{array}{c}\text { склоны, } \\
\text { низины, овраги, } \\
\text { смешенный лес, } \\
\text { теневые } \\
\text { цветники }\end{array}$ \\
\hline
\end{tabular}

Виды из Красной книги Москвы делятся на 5 категорий, поэтому в работе мы опирались на них, за исключением первой, куда относятся исчезнувшие виды (таблица $1)$.

Категория 0 - исчезнувшие виды после 1960 г в г. Москве; 1 категория - виды под угрозой исчезновения, численность которых сократилась до критического уровня; 2 категория - редкие или малочисленные виды с сокращающейся численностью, которые при дальнейшем проявлении на них негативных факторов за короткий срок могут попасть по угрозу исчезновения; 3 категория - уязвимые виды, изначально малочисленные в природе или обычные в соответствующих им местообитаниям, численность которых под воздействием специфических факторов может резко сократиться за короткий промежуток времени; 4 категория - неопределенные виды по статусу на сегодняшний день; 5 категория восстанавливаемые и восстанавливающиеся виды еще недавно сравнительно редкие в г. Москве, численность которых на территории города начала восстанавливаться в результате принятых мер или самопроизвольно.

Изученные виды, относятся в основном ко второй и третьей категории. Среди них встречаются виды, имеющие очень продолжительный по времени «пик декоративности» - 50-90 дней, у остальных он небольшой - 10-15 дней и средний 20-30 дней. У всех изученных видов декоративность листьев, форма растения, окраска листьев и цветков - продолжительная и сохраняется весь сезон.

Поскольку данные виды требуют особых условий выращивания, то для их сохранения и дальнейшего восстановления из семян или путем деления, их необходимо размещать в тех типах посадки и условиях, которые для них характерны в природе. Таким образом, при правильном размещении и осуществляемом уходе за насаждениями в условиях города, данные виды, не только придадут посадкам высокую декоративность в течение всего сезона, но и смогут успешно размножаться, осваивая новые территории или стать донором - источником посадочного материала для новых посадок. Это важно в связи с новым направлением в городском озеленении и заменой однолетних луковичных культур на многолетние, самовосстанавливающиеся и долговечные виды.

$$
* * *
$$

1. Аркадьева Н.В., Ханбабаева О.Е., Ханбабаев Р.К., Олейник С.С. Гарденотерапия, как способ самореализации и саморазвития для детей школьного возраста с ограниченными возможностями здоровья. Вестник ландшафтной архитектуры. 2019. № 17. С. 11-14.

2. Иванова И.В., Ханбабаева О.Е. Частное цветоводство. Раздел проектирование и оформление каменистого сада / Москва, 2012.

3. Иванова И.В., Ханбабаева О.Е. Декоративное садоводство с основами ландшафтного проектирования. Москва, 2013. Том Часть 2

4. Иванова И.В., Ханбабаева О.Е. Частное цветоводство. Раздел «Проектирование и оформление водоемов» Учебное пособие / Москва, 2012.

5. Лобозова А.В., Ханбабаева О.Е. Изучение биологических особенностей и оценка декоративных качеств сортов хосты. Доклады Тимирязевской сельскохозяйственной академии (см. в книгах). 2011. № 283-1. С. 762-766. 
6. Ковалева И.С., Мацнева А.Е., Ханбабаева О.Е., Мазаева А.С. Введение в культуру in vitro сеянцев флокса метельчатого (Phlox paniculata L.) Международный научный журнал. 2017. № 3. C. 79-84.

7. Ковалева И.С., Мацнева А.Е., Ханбабаева О.Е., Мазаева А.С., Сорокопудов В.Н. Разработка оптимальных условий длительного депонирования коллекции оздоровленных клонов флокса метельчатого (Phlox paniculata L.) Вестник КрасГАУ. 2019. № 8 (149). С. 47-51.

8. Мазаева А.С., Ковалева И.С., Мацнева А.Е., Ханбабаева О.Е. Инициация стерильных культур флокса метельчатого (Phlox paniculata L.). В сборнике: ДОКЛАДЫ ТСХА. Материалы международной научной конференции. 2018. С. 24-27.

9. Сорокопудов В.Н., Березкина И.В., Пирогова К.И., Скакова А.Г., Токарев Д.А., Ханбабаева О.Е., Ханбабаев Р.К. Изучение влияния занятий «скандинавской ходьбой» в связи с разработкой озеленения и благоустройства специальных маршрутов в парках г. Москвы. Естественные и технические науки. 2019. № 7 (133). С. 62-68.

10. Ханбабаева О.Е. Мультимедийное учебное пособие «Размножение декоративных растений». Свидетельство о регистрации базы данных RU 2013620650. Заявка № 2013620364 от 17.04.2013.

11. Ханбабаева О.Е., Мацнева А.Е., Сорокопудов В.Н. Особенности клонального микроразмножения сортов клематиса (Clematis L.) Вестник КрасГАУ. 2020. № 2 (155). C. 46-52.

12. Ханбабаева О.Е., Иванова И.В., Тазина С.В. Цветоводство с основами ландшафтного дизайна. Москва, 2019.

13. Shlapakova S.N., Beriozkina I.V., Hanbabayeva O.E., Sorokopudov V.N., Lukashov Ye.S. SELECTION OF HERBACEOUS PLANT ASSORTMENT FOR PARK GROUND COVER USING PLANTS OF NATURAL PHYTOCOENOSIS. В сборнике: BIO Web of Conferences. International ScientificPractical Conference "Agriculture and Food Security: Technology, Innovation, Markets, Human Resources” (FIES 2019). 2020. C. 00246. 